\title{
Imazamox detoxification and recovery of plants after application of imazamox to an imidazolinone resistant sunflower hybrid
}

\author{
D. BALABANOVA ${ }^{1,2 *}$, T. REMANS ${ }^{2}$, A. CUYPERS ${ }^{2}$, J. VANGRONSVELD ${ }^{2}$, and A. VASSILEV ${ }^{1}$ \\ Department of Plant Physiology and Biochemistry, Agricultural University of Plovdiv, BG-4000 Plovdiv, \\ Bulgaria $^{1}$ \\ Centre for Environmental Sciences, Hasselt University, BE-3590 Diepenbeek, Belgium ${ }^{2}$
}

\begin{abstract}
Imidazolinone herbicides combined with imidazolinone resistant (IMI-R) crops provide a tool for solving the important problem of the occurrence of weeds during the early growth stages of sunflower. These herbicides inhibit the synthesis of branched chain amino acids by interrupting the key enzyme acetohydroxyacid synthase (AHAS). We studied the imazamox detoxification in an IMI-R sunflower hybrid together with plant growth and photosynthetic performance. Inhibition of photosynthesis and growth were observed as initial effects of imazamox application. A slight decrease in AHAS activity was also noticed. These effects disappeared within two weeks after application. A fast and well-functioning detoxification mechanism for the herbicide, of which the content decreased for about $90 \%$ at $14 \mathrm{~d}$ after application, seems to be responsible for this. The activity of the xenobiotic detoxifying enzyme glutathione S-transferases (GSTs) significantly increased after imazamox application. Our results suggest that the metabolite glutathione serves as an auxiliary tool for imazamox detoxification through conjugation reactions realized by the GSTs, thereby taking part in the non-target mechanisms of resistance in IMI-R sunflower hybrids.
\end{abstract}

Additional key words: acetohydroxyacid synthase, chlorophyll, glutathione S-transferase, Helianthus annuus, photosynthesis.

\section{Introduction}

Sunflower (Helianthus annuus L.) is an important oilseed crop grown all over the world. Efficient control of harmful weeds is achieved by the use of herbicides with a different mode of action. The group of imidazolinonebased herbicides controls weeds through inhibition of the enzyme acetohydroxyacid synthase (AHAS, EC 2.2.1.6) in susceptible species. In IMI-R sunflower hybrids a spontaneous mutation results in site of action resistance of the target enzyme AHAS. As an implementation to the so-called gene-based resistance, non-target site mechanisms of resistance were also described to take a part in the imidazolinine resistance of the Imisun sunflower hybrids (Sala et al. 2012). From 2003 the Clearfield ${ }^{\circledR}$ technology based on a combination of both imazamox and imidazolinone resistant (IMI-R) sunflower hybrids has been commercialized (Pfenning et al. 2008). Imisun and CLPlus are two imidazolinone tolerance traits in sunflower determined by the expression of two alternative alleles at the AHAS1 locus, which are on the market as CL and CLPlus, respectively (Sala et al. 2011).

The primary site of action of imazamox is the AHAS, but the physiological effects of its action are diverse and not yet fully understood. A few days after the foliar application of imazamox, toxicity symptoms, such as chlorosis and necrosis, appear in developing leaves of sensitive plants (Cobb and Reade 2010). The earliest physiological effects observed, are changes in the amounts of some metabolites such as an increased free amino acid pool and decreased protein content which are related to cessation of protein synthesis (Shaner and Reider 1986). AHAS inhibition also leads to the accumulation of its substrate, 2-ketobutyrate (LaRossa and Schloss 1984). Also a rapid inhibition of cell division (Rost 1984) and consequently retarded growth due to the high susceptibility of meristematic tissues are common effects of AHAS inhibition (Shaner 1991).

Despite the relatively high tolerance of Clearfield ${ }^{\circledR}$ sunflower hybrids to imazamox, temporary yellowing and stunting of young leaves as well as inhibition of plant

Submitted 4 March 2019, last revision 8 November 2019, accepted 2 December 2019.

Abbreviations: AHAS - acetohydroxyacid synthase; CDNB - 1-chloro-2,4-dinitrobenzene; DAT - days after treatment; GSH - reduced glutathione; GSSG - oxidized glutathione; GST - glutathione-S-transferase; IMI-R - imidazolinone resistant.

Acknowledgements: This work is funded by an UHasselt BOF-BILA grant to DB in the frame of a collaboration between Hasselt University, Belgium and Agricultural University of Plovdiv, Bulgaria. The work was further supported by the UHasselt-Methusalem project 08M03VGRJ.

*Corresponding author; e-mail: da_balabanova@abv.bg 
height growth may occasionally occur after imazamox application (Pfenning et al. 2008, Sala et al. 2012). The negative impact can be even more pronounced in case of plants growing under stressful environmental conditions (drought, heat, waterlogging, etc.) (Pfenning et al. 2008). Decreased photosynthetic pigments content of IMI-R sunflower has been reported after imazapyr application (Ochogavia et al. 2014). We also observed decreased chlorophyll content in the young leaves of imazamoxtreated IMI-R sunflower plants (Balabanova and Vassilev 2015, Balabanova et al. 2016).

The degradation of imazamox in plants is taking place in several phases. In phase I imazamox has been reported to enhance the activity of cytochrome P450 monooxygenases (Kaspar et al. 2011). In a second phase, tolerant plants metabolise imazamox into the 5-hydroxymethyl metabolite, which is conjugated to glucose (Shaner 2003). The participation of glycosyltransferases in imazamox detoxification through glucose conjugation is reported also for IMI-R crop species such as wheat, where the two imazamox metabolites, hydroxy and glucoside derivatives were identified (Rojano-Delgado et al. 2015, DominguezMendez et al. 2017). There exists little information concerning a role for glutathione S-transferases (GSTs) in imazamox detoxification. Manabe (2007), using microarray analyses, reported that in IMI-R A. thaliana plants the first genes responding to imazamox treatment were genes encoding metabolites involved in stress responses such as cytochrome P450 monooxygenases, glycosyltransferases, and GSTs. More recently, GarciaGarijo (2014) reported an increase of the activitiy of GSTs after imazamox application in root nodules of some legume species. We proposed that, in addition to glucose conjugation, imazamox might be detoxified through GSTs in a IMI-R sunflower hybrid, at least during the first $24 \mathrm{~h}$ after the treatment (Balabanova et al. 2018). The possible participation of this enzyme family in imazamox detoxification during next days remains unclear.

The degradation rate of the herbicides is a very important tool regarding the non-target herbicide resistance mechanisms (Yuan et al. 2006). Clearfield ${ }^{\circledR}$ crops generally possess an enhanced ability to metabolize IMI herbicides before they reach their sites of action (DominguezMendez et al. 2017). Rapid imazamox metabolization has been reported to increase selectivity of some legume crops (Bukun et al. 2012). These authors reported that the differential sensitivity between dry bean and red lentil is due to rapid imazamox metabolism in the resistant dry bean compared to the sensitive red lentil, where approximately $90 \%$ of the imazamox was metabolized by dry bean within $96 \mathrm{~h}$ after treatment. On the contrary, Dominguez-Mendez (2017) have observed that the lower sensitivity of IMI-R compared to IMI-S (imidazolinonesensitive) wheat hybrids is due to lower absorption and translocation of the herbicide imazamox. Rojano-Delgado (2015) reported that some IMI-R wheat cultivars possess a complementary resistance mechanism to AHAS inhibitors based on an enhanced metabolism of imazamox, allowing them to metabolise approximately $68 \%$ of the herbicide until $5 \mathrm{~d}$ after treatment. There exists no information about the degradation ability of IMI-R sunflower.

For the recovery of plants after growth inhibition together with the degradation rate, the overall physiological state of the plants is very important. Vercampt (2016) reported that after treatment of Brassica napus with the recommended dose of the herbicide metazachlor, the energy from photosynthesis can be directed to protection mechanisms of the photosynthetic apparatus rather than to growth. The reliability of the photosynthetic apparatus indeed benefits plant growth and recovery.

To better characterize the imazamox-induced modulation of the physiological performance of IMI-R sunflower plants, we monitored the imazamox content in the leaves $(1,7$, and $14 \mathrm{~d}$ after treatment, DAT) and determined selected parameters at 7 and 14 DAT (AHAS activity, AHAS1 gene expression, reduced and oxidized glutathione content (GSH and GSSG, respectively), activity of GSTs, photosynthetic pigments profiles, leaf gas exchange and plant growth. The aim of the study was to establish whether GSTs enzymes participate in imazamox detoxification until its complete degradation in IMI-R sunflower plants and to evaluate the possible involvement of photosynthetic performance in their growth recovery.

\section{Materials and methods}

Plants and treatments: In this study, sunflower (Helianthus annuus L.) Clearfield ${ }^{\circledR}$ hybrid Meldimi carrying haplotype 5 of the AHAS1 gene (Imisun trait) were used. The seeds were washed with distilled water and germinated in Petri dishes for three days at $22^{\circ} \mathrm{C}$. The seedlings were transplanted to pots ( 4 plants per pot) filled with a half-strength modified Hoagland nutrient solution and placed in a growth chamber (a 14-h photoperiod, a photosynthetic photon flux density at the leaf level of $250 \mu \mathrm{mol} \mathrm{m}{ }^{-2} \mathrm{~s}^{-1}$, day/night temperatures of $24 / 22 \pm 1{ }^{\circ} \mathrm{C}$, and a relative humidity of $60 \%$ ). An experimental design, including 2 treatments, was set up with plants at stage of 4 - 6 true leaves: 1) non-treated plants (control) and 2) application of imazamox by spraying it on the leaves in a rate of $132 \mu \mathrm{g}$ per plant. Four plants were used for each measurement. The analyses were performed on the second, third, and fourth true leaf pairs. Sampling was done at 1,7 , and $14 \mathrm{~d}$ after treatment (DAT) and aliquots were immediately frozen in liquid nitrogen and stored at $-80{ }^{\circ} \mathrm{C}$ prior to further analysis.

Dry mass of plants and leaf area were determined at 7 and 14 DAT. The plants were dried in paper at $60^{\circ} \mathrm{C}$ for two days. The leaf area was measured by an electronic area meter (NEO-2, TU-Sofia, Bulgaria).

Residues of imazamox: After homogenization and extraction of leaf tissue $(3 \mathrm{~g})$ by $30 \mathrm{~cm}^{3}$ acetone, $30 \mathrm{~cm}^{3}$ of a mixture of petroleum ether/dichloromethane (1/1) was added. Subsequently, $20 \mathrm{~g}$ of $\mathrm{NaSO}_{4}$ was dissolved in this mixture, followed by $30 \mathrm{~min}$ incubation at room temperature. Fifteen $\mathrm{cm}^{3}$ from the solvent was evaporated to dryness using a rotary evaporator at $40{ }^{\circ} \mathrm{C}$ bath 
temperature and the residue was dissolved in $10 \mathrm{~cm}^{3}$ methanol/water (1/1) mixture.

Samples were analysed using a liquid chromatography tandem quadrupole mass spectrometer Acquity XevoTQ UPLS/MS/MS (Waters, Milford, MA, USA), using a column SunFire, C18, $2.1 \times 150 \mathrm{~mm}, 3.5 \mu \mathrm{m}$, combined with pre-column SunFire, C18, $2.1 \times 10 \mathrm{~mm}, 3.5 \mu \mathrm{m}$, both from Waters. LC-MS ion scans for the $\mathrm{m} / \mathrm{z} 306.1$ in positive ion mode were performed at a cone voltage of $35 \mathrm{~V}$ and a collision energy of $20 \mathrm{eV}\left(1^{\text {st }}\right.$ transition $\left.\mathrm{m} / \mathrm{z} 261.05\right)$ and collision energy of $27 \mathrm{eV}$ ( $2^{\text {nd }}$ transition $\left.\mathrm{m} / \mathrm{z} 85.95\right)$.

Protein content: Protein extraction was performed according to Schröder and Götzberger (1997). Frozen plant material $(0.5 \mathrm{~g})$ was powdered and $5 \mathrm{~cm}^{3}$ of freshly prepared extraction buffer [0.1 M Tris/HCl, $\mathrm{pH}$ 7.8, $5 \mathrm{mM}$ EDTA, $5 \mathrm{mM}$ dithioerythritol, $1 \%(\mathrm{~m} / \mathrm{v})$ Nonidet P40, $1 \%(\mathrm{~m} / \mathrm{v})$ polyvinylpyrrilidone] was added. After incubation $\left(4{ }^{\circ} \mathrm{C}\right.$, $30 \mathrm{~min})$ and centrifugation $\left(50000 \mathrm{~g}, 4{ }^{\circ} \mathrm{C}, 30 \mathrm{~min}\right)$, the proteins in the crude extract were precipitated by addition of ammonium sulphate in two steps of 40 and $80 \%$ saturation, respectively. Protein solutions were centrifuged after each step (50 $\left.000 \mathrm{~g}, 4{ }^{\circ} \mathrm{C}, 30 \mathrm{~min}\right)$ and pellets were finally resuspended in $2 \mathrm{~cm}^{3}$ of $25 \mathrm{mM}$ Tris/ $\mathrm{HCl}$ buffer $\mathrm{pH}$ 7.8. This step was followed by desalting using Sephadex PD-10 columns. Protein content was determined spectrophotometrically using the Biorad (Hercules, CA, USA) protein assay and a bovine albumin as standard (Bradford 1976).

Glutathione content: Content of GSH and GSSG were determined according to the method described by Queval and Noctor (2007). Frozen leaf tissue was ground, homogenized in $200 \mathrm{mM} \mathrm{HCl}$, and centrifuged (12 $000 \mathrm{~g}$, $10 \mathrm{~min}$ ). $\mathrm{An} \mathrm{NaH}_{2} \mathrm{PO}_{4}$ buffer was added to the supernatant and $\mathrm{pH}$ was adjusted to 4.5. Estimations of GSH and GSSG are based on the glutathione reductase (GR)-dependent reduction of 5,5-dithiobis(2-nitro-benzoic acid (DTNB), monitored at $412 \mathrm{~nm}$. The $\mathrm{pH}$ adjusted supernatant was incubated with 2-vinyl-pyridine (2-VP) at $20{ }^{\circ} \mathrm{C}$ for $30 \mathrm{~min}$. To determine total glutathione, the supernatant was added in triplicate to a 96-well plate containing $200 \mathrm{mM} \mathrm{NaH}{ }_{2} \mathrm{PO}_{4}-10 \mathrm{mM}$ EDTA buffer (pH 7.5), $10 \mathrm{mM}$ NADPH, $12 \mathrm{mM}$ DTNB, and $0.06 \mathrm{~cm}^{3}$ of distilled $\mathrm{H}_{2} \mathrm{O}$. The reaction was started by adding GR $\left(20 \mathrm{U} \mathrm{cm}^{-3}\right)$ and the rate of DTNB reduction was monitored. the content of total glutathione was calculated relative to a GSH standard curve and was corrected for GSH-independent reduction of DTNB by subtraction of the mean value of duplicate blank assays (no GSH). GSSG was determined according to the same principle after incubation with 2-VP to complex GSH. The final standard was also subjected to incubation with 2-VP. Content of GSSG was calculated as for total glutathione.

Glutathione-S-transferase activity: Glutathione-Stransferase (GST, EC 2.5.1.18) activity assays were carried out following the method of Habig (1974). For determination of GST activity, 0.1 M Tris/ $\mathrm{HCl}$ buffer, $\mathrm{pH}$ 6.4, was used for two model substrates 1-chloro- 2,4-dinitrobenzene (CDNB, a coefficient of absorbance $\left.\varepsilon=9.6 \mathrm{mM}^{-1} \mathrm{~cm}^{-1}\right)$ and the herbicide fluorodifen $\left(\varepsilon=3.1 \mathrm{mM}^{-1} \mathrm{~cm}^{-1}\right)$. The coefficients were taken from Habig et al. (1974) and Scalla and Roulet (2002). In all above-mentioned assays, the content of GSH as well as of the model substrates were $1 \mathrm{mM}$. One unit (U) of GST activity was defined as an amount of the enzyme catalyzing reaction of $1 \mu \mathrm{mol}$ of substrate per minute.

Activity of AHAS was determined according to Ray (1984) with some modifications. This assay detects the AHAS product of acetolactate after conversion into acetoin. Leaf tissue $(2 \mathrm{~g})$ was ground in $6 \mathrm{~cm}^{3}$ of extraction buffer $[(0.1 \mathrm{M}$ potassium phosphate $(\mathrm{pH} 7.5)$ containing sodium pyruvate $(0.1 \mathrm{M})$, thiamine pyrophosphate $(0.5 \mathrm{mM}), \mathrm{MgCl}_{2}(0.5 \mathrm{mM})$, flavin adenine dinucleotide $(\mathrm{FAD}, 10 \mu \mathrm{M})$ and $10 \%(\mathrm{v} / \mathrm{v})$ glycerol] and PVP was added. The homogenates were filtered through a layer of cheese cloth and centrifuged at $14000 \mathrm{~g}$ and $4{ }^{\circ} \mathrm{C}$ for $20 \mathrm{~min}$. Proteins were precipitated from the supernatant at $50 \%$ saturation of ammonium sulphate and the solution was centrifuged at $14000 \mathrm{~g}$ and $4{ }^{\circ} \mathrm{C}$ for $25 \mathrm{~min}$. The supernatant was discarded and pellets were resuspended in potassium phosphate $(0.1 \mathrm{M}, \mathrm{pH} 7.5)$ containing sodium pyruvate $(20 \mathrm{mM})$ and $\mathrm{MgCl}_{2}(0.5 \mathrm{mM})$.

Activity of AHAS was assayed by adding $0.1 \mathrm{~cm}^{3}$ of enzyme extract to $0.5 \mathrm{~cm}^{3}$ of reaction mixture $[20 \mathrm{mM}$ potassium phosphate $(\mathrm{pH} 7.5)$ containing sodium pyruvate $(20 \mathrm{mM})$, thiamine pyrophosphate $(0.5 \mathrm{mM}), \mathrm{MgCl}_{2}$ $(0.5 \mathrm{mM})$ and FAD $(10 \mu \mathrm{M})]$. The reaction mixture was dark incubated at $37{ }^{\circ} \mathrm{C}$ for $1 \mathrm{~h}$ and the reaction was subsequently terminated by adding $0.05 \mathrm{~cm}^{3}$ of $\mathrm{H}_{2} \mathrm{SO}_{4}$ $(3 \mathrm{M})$. Then, $0.5 \mathrm{~cm}^{3}$ of $0.5 \%(\mathrm{~m} / \mathrm{v})$ creatine was added and the solution was incubated at $60^{\circ} \mathrm{C}$ for $15 \mathrm{~min}$ in darkness. The added sulfuric acid terminated the AHAS reaction and decarboxylated the enzyme product acetolactate to acetoin. Acetoin was detected as a coloured complex $\left(\mathrm{A}_{525}\right)$ formed after addition of $5 \%(\mathrm{~m} / \mathrm{v}) \alpha$-naphthol (freshly prepared in $2.5 \mathrm{M} \mathrm{NaOH}$ ) and dark incubation at $60{ }^{\circ} \mathrm{C}$ for $15 \mathrm{~min}$. A standard curve was constructed using commercial acetoin.

Gene expression analysis: Frozen $\left(-80^{\circ} \mathrm{C}\right)$ plant tissue $(50 \mathrm{mg}$ ) was ground in liquid nitrogen using mortar and pestle. RNA was extracted using the miRVANA total RNA isolation buffer, according to the manufacturer's instructions (Life Technologies, Paisley, UK). The RNA concentration and purity were determined spectrophotometrically using the NanoDrop ND-1000 (NanoDrop Technologies, Wilmington, DE, USA). To remove genomic DNA, $1 \mu \mathrm{g}$ RNA was treated using the $T U R B O$ DNA-free kit according to the manufacturer's instructions (Life Technologies). First strand cDNA synthesis was performed with $1 \mu \mathrm{g}$ total RNA using the High Capacity reverse transcription kit and a combination of oligo(dT)-primers and random hexamers according to the manufacturer's instructions (Life Technologies). The cDNA sample was diluted 10 -fold in 1/10 TE-buffer $(1 \mathrm{mM}$ Tris- $\mathrm{HCl}, 0.1 \mathrm{mM}$ EDTA, $\mathrm{pH} 8)$ and stored at $-20^{\circ} \mathrm{C}$. Quantitative PCR was performed with the 7500 Fast realtime PCR cycler (Applied Biosystems). PCR reactions were 
carried out in a total volume of $10 \mathrm{~mm}^{3}$, containing $2 \mathrm{~mm}^{3}$ of cDNA sample, $5 \mathrm{~mm}^{3}$ of Fast SYBR Green Master Mix (Life Technologies) and $300 \mathrm{nM}$ of each primer. Primer sequences of reference genes were according to Fernandez (2011). Sequences of the AHAS1 genes were searched through Gene Index (http://compbio.dfci.harvard.edu/cgibin/tgi/geneprod_search.pl). Specificity of the primers was verified by $B L A \bar{S} T$ and melting curve analysis after realtime PCR.

The amplification efficiencies of all primer sets were investigated by measuring a 2-fold serial dilution $(\mathrm{E}=10(-1 /$ slope $)$ method $)$ and were approved when they were greater than 1.8. Genes and primer sequences for RT-qPCR are listed in Table 1 Suppl. After geNorm analysis (Vandesompele et al. 2002), two reference genes (ACT and PEP) were selected for normalization.

Relative quantities were calculated as $2^{-\Delta \mathrm{Cq}}$ and normalized using the normalization factor based on the geometric mean of the expressions of both reference genes. Adherence of the RT-qPCR to $M I Q E$ guidelines (Bustin et al. 2010) is listed in Table 2 Suppl.

Sequencing the $\boldsymbol{A H A S}$ gene: The genomic DNA was extracted from conventional IMI-S and IMI-R hybrid plants using a DNeasy mini kit (Qiagen, Valencia, CA, USA). The conventional IMI-S hybrid (cv. Albena) was used only to confirm the AHAS1 gene mutation in the Clearfield hybrid Mildimi. Primers specific for the $A H A S 1$ gene were designed (AHAS1-F: 5'-GACCGTTACCGGTGCAGCCT-3' and AHAS1-R: 5'-CACGATCATCAAACCGCACC-3', sequences corresponding to haplotype 1) surrounding the single nucleotide polymorphism delivering IMI resistance. The region was amplified using these primers and the High Fidelity PCR Enzyme Mix (Thermo Scientific, Waltham, MA, USA) according to the manufacturer's instructions and using a primer annealing temperature of $70{ }^{\circ} \mathrm{C}$. The PCR products were sequenced by Macrogen (Seoul, South Korea) and aligned to the Genbank haplotype 1 (AY541451.1) and haplotype 5 (AY541455.1) sequences using ClustalW2 (The European Bioinformatics Institute; http://www.ebi.ac.uk/).

Content of photosynthetic pigments and leaf gas exchange: Chlorophyll (Chl) $a, \mathrm{Chl} b$, and total carotenoids (Car) were extracted in $85 \%$ acetone, measured spectrophotometrically and calculated according to the formulae of Lichtenthaler (1987).

Leaf gas exchange parameters: net photosynthetic rate $\left(\mathrm{P}_{\mathrm{N}}\right)$, transpiration rate $(\mathrm{E})$, stomatal conductance $(\mathrm{g} s)$, and internal $\mathrm{CO}_{2}$ concentration $\left(\mathrm{c}_{\mathrm{i}}\right)$ were determined on the fully developed leaves (closest to the top) at 14 DAT with an open photosynthetic system LCpro+ (ADC, Hoddesdon, UK). The conditions in a leaf chamber in the time of stationary measurements were: a photosynthesis active radiation of $250 \mu \mathrm{mol} \mathrm{m} \mathrm{m}^{-1} \mathrm{~s}^{-1}$, a $\mathrm{CO}_{2}$ concentration of $450 \mu \mathrm{mol} \mathrm{mol}{ }^{-1}$, a leaf temperature of $25^{\circ} \mathrm{C}$, a relative humidity of $60-65 \%$.

Statistical analysis: Statistical analysis was performed using one-way $A N O V A$. Based on these $A N O V A$ results, a post-hoc Duncan test for mean comparison was performed at a $95 \%$ confidence level to test for significant differences between treatments.

\section{Results}

The content of imazamox in leaves of imazamoxtreated sunflower plants were determined at 1, 7, and 14 DAT (Fig. 1). The content of imazamox in the plants significantly decreased over time from about $19 \mathrm{mg} \mathrm{kg}^{-1}$ (1 DAT) to $1.5 \mathrm{mg} \mathrm{kg}^{-1}$ (14 DAT). At 7 DAT, the imazamox content was about $7.5 \mathrm{mg} \mathrm{kg}^{-1}$, which represents about $37 \%$ of the initial content.

In sunflower plants, the activities of the AHAS and the leaf protein content were determined at 7 and 14 DAT (Fig. 2). The protein content was lower in imazamoxtreated plants compared to non-treated plants (Fig. 2A). The AHAS activity after imazamox treatment was lower than in non-treated plants (Fig. 2B). To find out whether the expression of the AHAS1 gene was affected by imazamox treatment or not, we determined the relative gene expression. At 14 DAT, however, the expression of the AHAS1 gene was not affected by the treatment.

At 7 and 14 DAT, the total glutathione content in imazamox treated sunflower plants was much higher in comparison with non-treated plants but no differences in the ratio GSH/GSSG were observed between treated and control plants.

At 7 DAT, IMI-R imazamox treated plants showed slightly increased transcriptions of $\gamma$-glutamylcysteine synthetase and glutathione synthetase, involved in the biosynthesis of glutathione, were observed. The results supported that imazamox induced GSH accumulation via increased expression of synthesis genes (Fig. 3B).

To estimate the impact of imazamox treatment on the xenobiotic metabolism of sunflower plants the activity

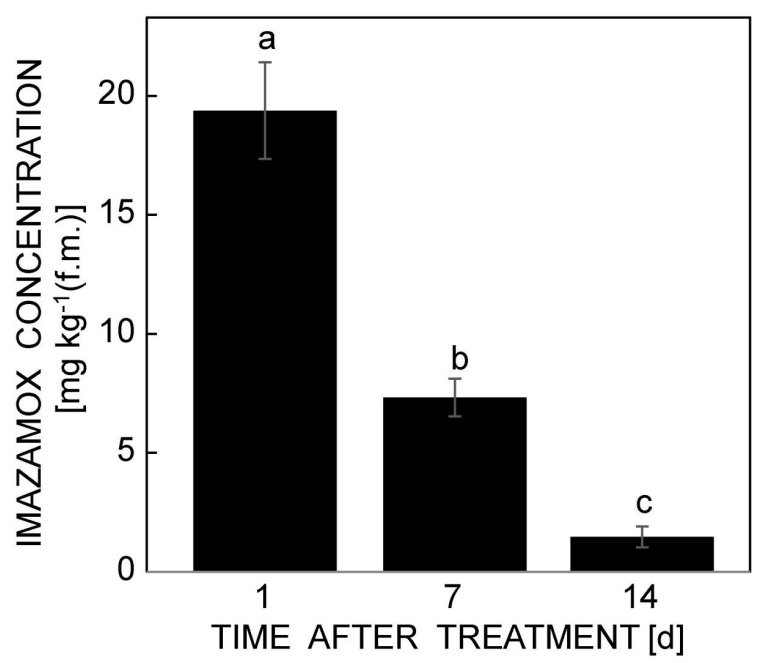

Fig. 1. Content of imazamox in imidazoline resistant sunflower plants after 1, 7, and $14 \mathrm{~d}$ treatment with the herbicide imazamox. Means \pm SDs, $n=3$ biological replicates; different letters indicate significant differences $(P<0.05)$. 


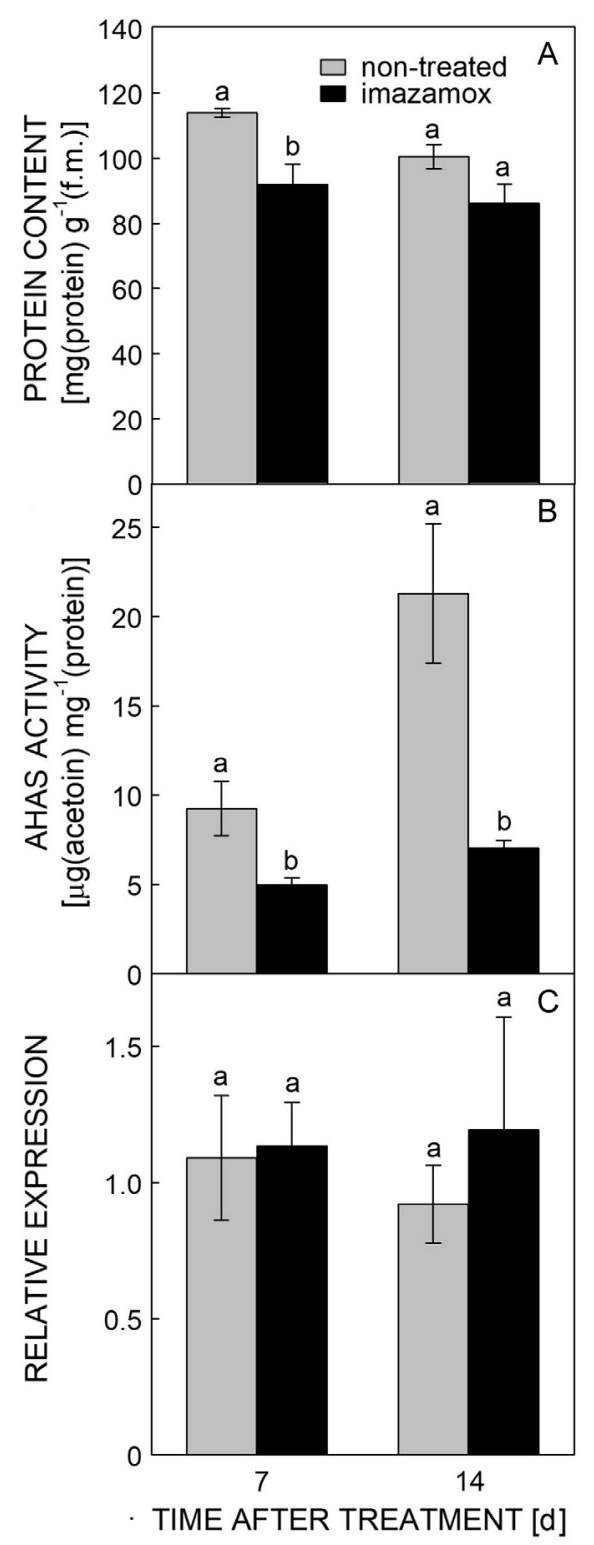

Fig. 2. Protein content $(A)$, activity of acetohydroxyacid synthase (AHAS) (B), and the relative expression of AHAS1 (C) in imidazoline resistant sunflower plants 7 and $14 \mathrm{~d}$ after imazamox teratment. Means \pm SDs, $n=3$ biological replicates; different letters indicate significant differences $(P<0.05)$.

of glutathione-S-transferases (GSTs) was determined with two substrates 1-chloro-2-nitrobenzen (CDNB) and fluorodifen. The GSTs activity with both substrates was higher after imazamox application (Fig. 3C). The GSTCDNB activity was enhanced at both 7 DAT and 14 DAT by 52 and $65 \%$, respectively. Also the GST-fluorodifen activity was increased by 28 and $57 \%$ at the same time.

Symptoms of imazamox toxicity were observed at 7 DAT. Plants treated with imazamox only showed a strong growth inhibition at about $30 \%$ (according to phytotoxicity scale used throughout the greenhouse trials, Monchiero et al. 2015). From the growth parameters (Fig. 4) is obvious that the treatment had negative effects on leaf area and plant dry mass. At 14 DAT, the growth
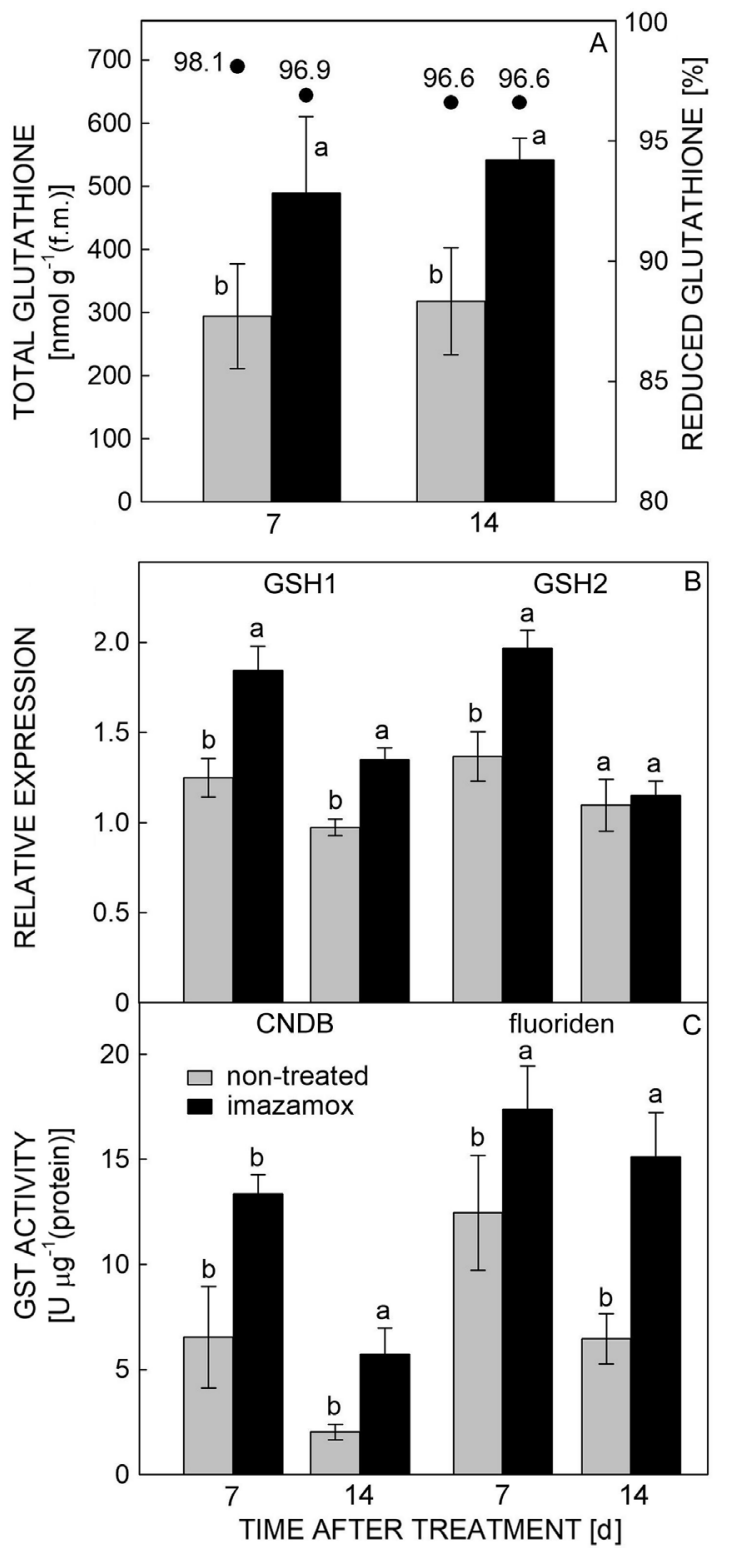

Fig. 3. $A$ - Total glutathione content and percentage of reduced glutathione; $B$ - relative expressions of $\gamma$-glutamylcysteine synthetase (GCS, EC 6.3.2.2.) and glutathione synthetase (GS, EC 6.3.2.3.); $C$ - glutathione S-transferase (GST) activity in imidazoline resistant sunflower plants at 7 and 14 days after treatment (DAT) with the herbicide imazamox. Means \pm SDs, $n=3$ biological replicates; different letters indicate significant differences $(P<0.05)$.

inhibition of imazamox-treated sunflower plants was still noticeable, but in comparison with 7 DAT it was less.

To appraise the photosynthetic performance of the plants, leaf gas exchange parameters and photosynthetic pigments were determined (Table 1). It was obvious that imazamox treatment inhibited $\mathrm{P}_{\mathrm{N}}$. This inhibition was most marked at 7 DAT $(24.7 \%)$ compared to values of non-treated plants. This inhibition was not caused by a decreased $c_{i}$ since there were no significant differences in $\mathrm{c}_{\mathrm{i}}$ at this time point. At 14 DAT, there was still a significant inhibition of $\mathrm{P}_{\mathrm{N}}$, but it was less pronounced. No significant 


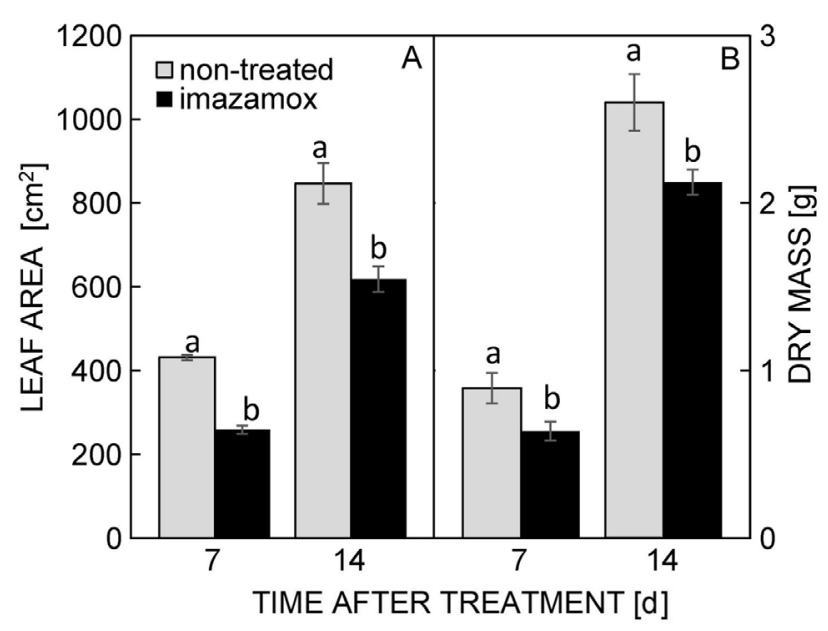

Fig. 4. Growth parameters leaf area $(A)$ and dry mass $(B)$ of imidazoline resistant sunflower plants 7 and 14 days after treatment (DAT) with the imazamox. Means \pm SDs, $n=3$ biological replicates; different letters indicate significant differences $(P<0.05)$.

differences were observed in E between treated and control plantst. The stomatal conductance plays a role in leaf-gas exchange; we observed lowered $g_{s}$ at both 7 and 14 DAT (12 and $21 \%$, respectively).

The content of the photosynthetic pigments in the leaves of imazamox-treated sunflower at 7 DAT were significantly lower compared to non-treated plants (31.5, 19.1 , and $22.3 \%$ for Chl $a$, Chl $b$, and Car, respectively). A similar pattern was observed in plants at 14 DAT, where the Chl $a$ content was significantly lower in imazamoxtreated plants compared to non-treated control plants ( $25 \%$ reduction).

\section{Discussion}

The responses of crop plants to highly selective herbicides such as imidazolinines depends on many factors including application rate, sensitivity of the crops, environmental conditions during and after the treatment, and many others. Environmental factors indeed were reported to significantly influence the activity and effects of herbicides (Kudsk and Kristensen 1992), which explains differences in herbicide effects on plants between strictly controlled greenhouse or growth chamber environments and field conditions. Even in resistant hybrids, occasionally, slight growth retardation of sunflower or temporary yellowing were reported after imazamox application (Pfenning et al. 2008). In our study, we worked in controlled conditions and used a dose of imazamox that was high enough to cause noticeable toxicity symptoms in IMI-R sunflower plants. A transient growth inhibition was observed, which was most obvious at 7 DAT at which the fresh and dry masses and the leaf area were lower comparted to the untreated controls (Fig. 4). Growth retardation and decreased shoot biomass production after imazamox application were also reported by Rojano-Delgado (2015) in a study on resistant and susceptible wheat cultivars. At 14 DAT phytotoxicity symptoms were still noticeable, but only on older leaves and to a lower extent.

The photosynthetic performance of crop plants is very sensitive and can be easily disturbed by many stress factors, including herbicide application. Herbicides may affect directly or indirectly different gas exchange parameters like stomatal conductance, synthesis/ degradation of photosynthetic pigments, light reactions, Calvin cycle reactions, transport of photo-assimilates, etc. Inhibitions of $\mathrm{CO}_{2}$ fixation and electron transport have already been reported in some Clearfield ${ }^{\circledR}$ crops such as wheat and rice (Jimenez et al. 2015, Sousa et al. 2013). Although inhibition of photosynthesis is not a direct site of action of imazamox, our study also indicated

Table 1. Photosynthetic pigments and gas exchange parameters in the imidazoline resistant sunflower hybrid 7 and 14 days after treatment (DAT) with imazamox. Means \pm SDs, $n=3$ biological replicates; different letters mark significant differences $(P<0.05)$.

\begin{tabular}{|c|c|c|c|c|}
\hline Parameters & Units & Treatments & 7 DAT & 14 DAT \\
\hline \multirow[t]{2}{*}{ Chlorophyll $a$} & \multirow[t]{2}{*}[\mathrm{mg}\mathrm{g}^{-1}\text{(f.m.)}]{} & non-treated & $1.54 \pm 0.23$ (a) & $1.91 \pm 0.06$ (a) \\
\hline & & imazamox & $1.06 \pm 0.08(b)$ & $1.43 \pm 0.09(b)$ \\
\hline \multirow[t]{2}{*}{ Chlorophyll $b$} & \multirow{2}{*}[\mathrm{mg}\mathrm{g}^{-1}\text{(f.m.)}]{} & non-treated & $0.48 \pm 0.08$ (a) & $0.60 \pm 0.03(\mathrm{a})$ \\
\hline & & imazamox & $0.39 \pm 0.01(b)$ & $0.45 \pm 0.04(b)$ \\
\hline \multirow[t]{2}{*}{ Carotenoids } & \multirow{2}{*}[\mathrm{mg}\mathrm{g}^{-1}\text{(f.m.)}]{} & non-treated & $0.40 \pm 0.04$ (a) & $0.48 \pm 0.02(\mathrm{a})$ \\
\hline & & imazamox & $0.31 \pm 0.01(b)$ & $0.39 \pm 0.03(b)$ \\
\hline \multirow[t]{2}{*}{ Net photosynthetic rate } & \multirow{2}{*}[\mu\mathrm{mol}(\mathrm{CO}_{2})\mathrm{m}^{-2}\mathrm{s}^{-1}]{} & non-treated & $20.80 \pm 0.20(\mathrm{a})$ & $21.80 \pm 0.60$ (a) \\
\hline & & imazamox & $16.00 \pm 1.20(b)$ & $20.90 \pm 0.70$ (a) \\
\hline \multirow[t]{2}{*}{ Transpiration rate } & \multirow[t]{2}{*}[\mathrm{mmol}(\mathrm{H}_{2}\mathrm{O})\mathrm{m}^{-2}\mathrm{s}^{-1}]{} & non-treated & $3.47 \pm 0.20$ (a) & $2.97 \pm 0.20(\mathrm{a})$ \\
\hline & & imazamox & $3.25 \pm 0.20(\mathrm{~b})$ & $3.02 \pm 0.10(\mathrm{a})$ \\
\hline \multirow[t]{2}{*}{ Stomatal conductance } & \multirow[t]{2}{*}[\mathrm{mol}(\mathrm{H}_{2}\mathrm{O})\mathrm{m}^{-2}\mathrm{s}^{-1}]{} & non-treated & $0.42 \pm 0.06$ (a) & $0.38 \pm 0.04(\mathrm{a})$ \\
\hline & & imazamox & $0.37 \pm 0.05(b)$ & $0.32 \pm 0.02(b)$ \\
\hline \multirow[t]{2}{*}{ Internal $\mathrm{CO}_{2}$ concentration } & \multirow[t]{2}{*}[\mu\mathrm{mol}\mathrm{mol}{}^{-1}]{} & non-treated & $315.60 \pm 18.0(a)$ & $296.90 \pm 10.4(b)$ \\
\hline & & imazamox & $328.60 \pm 8.60$ (a) & $338.90 \pm 20.5$ (a) \\
\hline
\end{tabular}


suppression of $\mathrm{P}_{\mathrm{N}}$ in sunflower plants caused by imazamox treatment. The decreased $\mathrm{CO}_{2}$ assimilation could be due to the decreased content of photosynthetic pigments and the lower $g_{s}$ (Table 1). The imidazolinone herbicides are slow acting which might explain the absence of an effect on the photosynthetic rate at 1 DAT (data not shown). The inhibitory effect of imazamox on sunflower was most pronounced at 7 DAT, which corresponds to Gaston (2002) who also reported a significant reduction of $\mathrm{P}_{\mathrm{N}} 7$ days after application of imazethapyr to pea plants.

The kinetics of the photosynthetic performance of imazamox-treated sunflower plants ( 7 and 14 DAT) revealed a tendency of recovering. This recovery of the photosynthetic apparatus and the gas exchange is inevitably connected to a general restoration of the overall plant status and growth performance. Such a tendency for photosynthesis recovering after imazamox treatment was also reported for IMI-R wheat cultivars (Jimenez et al. 2015). In addition, evidence exists that imazamox should have negative effects on stomatal numbers in sunflower (Anastasov 2010) or sink strength and utilization of saccharides in imidazolinone-treated plants (Zabalza et al. 2004, Qian et al. 2011).

Although the AHAS activity was inhibited in plants treated by the imazamox compared to the untreated controls at 7 and 14 DAT, it was obvious that it was slightly recovering at 14 DAT. This could be due to detoxification of imazamox since the content of nonbound imazamox considerably decreased from 1 to 14 DAT (Fig. 1). It has been reported that a principal mechanism of imazamax detoxification in IMI-R wheat is through glucose conjugation (Rojano-Delgado et al. 2015, Dominguez-Mendez et al. 2017). Glutathione (GSH) is a key metabolite in plants used also by the GSTs for detoxification of toxic xenobiotics such as herbicides (Lamoureux and Rusness 1993, Marrs 1996, Foyer et al. 2001, Jozefczak et al. 2012). In a previous study we found that in IMI-R sunflower GSTs showed increased activity compared to an IMI-S cultivar, which suggests the participation of glutathione in imazamox detoxification in sunflower (Balabanova et al. 2018). In the current study we investigated the activities of GSTs from 7 to 14 DAT, when the plants demonstrated obvious signs of recovery. The activities of GSTs in imazamox treated sunflower plants were higher than in non-treated at both, 7 and 14 DAT (Fig. 3C). In addition, the amount of glutathione (Fig. 3A) and the expressions of $\gamma$-glutamylcysteine synthetase and glutathione synthetase (Fig. $3 B$ ) were also increased. All together, these results indicate that glutathione participated in the detoxification of imazamox in IMI-R sunflower by a conjugation reaction catalysed by GSTs family. Of course, this does not disregard detoxification of imazamox through glucose conjugation, which might even be the predominant detoxification route in sunflower. An additional mechanism to dispose the imazamox and enhance the plant herbicide tolerance could also be exudation of the molecules via the roots as has been reported for glyphosate (Coupland and Lutman 1982) or auxins (Mithila et al. 2011). This hypothesis needs further experiments.

In conclusion, also in IMI-R sunflower plants, the
AHAS activity is temporarily inhibited after application of the herbicide imazamox, which leads to a growth retardation. Application of imazamox inhibits the leaf gas exchange in IMI-R sunflower plants. This effect is slightly detectable from 1 DAT and most distinct at 7 DAT; after that, the inhibition of the photosynthetic activity gradually disappears and two weeks after the application of imazamox it reaches a level close to untreated control plants. Our results also indicate that recovery is occurring after some time, since imazamox is rapidly metabolized. Glutathione is contributing to imazamox detoxification through conjugation reactions realized by the GSTs enzyme family and thus is a part of the non-target site mechanisms of resistance in Imisun sunflower hybrids.

\section{References}

Anastasov, H.: Influence of imazamox on some anatomic indices in the leaves of sunflower plant (Helianthus annuus L.). Gen. appl. Plant Physiol. 36: 64-68, 2010.

Balabanova, D.A., Paunov, M., Goltsev, V., Cuypers, A., Vangronsveld, J., Vassilev, A.: Photosynthetic performance of the imidazolinone resistant sunflower exposed to single and combined treatment by the herbicide imazamox and an amino acid extract. - Front Plant Sci. 7: 1559, 2016.

Balabanova, D., Remans, T., Vassilev, A., Cuypers, A., Vangronsveld, J.: Possible involvement of glutathione S-transferases in imazamox detoxification in an imidazolinone-resistant sunflower hybrid. - J. Plant Physiol. 221: 62-65, 2018.

Balabanova, D. Vassilev, A.: Response of sunflower Clearfield hybrids to both recommendable and higher doses of imazamox herbicide - Agr. Sci. 8: 18:41-46, 2015.

Bradford, M.M.: A rapid and sensitive method for the quantitation of microgram quantities of protein utilizing the principle of protein dye-binding. - Anal Biochem 72: 248-254, 1976.

Brown, M.A., Chiu, T.Y.: Miller P.: Hydrolytic Activation versus oxidative degradation of Assert herbicide, an imidazolinone aryl-carboxylate, in susceptible wild oat versus tolerant corn and wheat. - Pestic. Biochem. Physiol. 27: 24-29, 1987.

Bukun, B., Nissen, S.J., Shaner, D.L., Vassos, J.D.: Imazamox absorption, translocation, and metabolism in red lentil and dry bean. - Weed Sci. 60: 350-354, 2012.

Bustin, S.A., Beaulieu, J., Huggett, J., Jaggi, R., Kibenge, F.S.B., Olsvik, P.A., Penning, L.C., Toegel, S.: Practical implementation of minimum standard guidelines for fluorescence-based quantitative real-time PCR experiments. BMC Plant Biol. 11: 74, 2010.

Coupland, D., Lutman, P. J. W.: Investigations into the movement of glyphosate from treated to adjacent untreated plants. - Ann. appl. Biol. 101: 315-321, 1982.

Cobb, A., Reade, J.P.H.: Herbicides and Plant Physiology. Wiley-Blackwell, Oxford 2010.

Domínguez-Mendez, R., Alcántara-de la Cruz, R., RojanoDelgado, A., Fernández-Moreno, P.T., Aponte R, De Prado, R.: Multiple mechanisms are involved in new imazamoxresistant varieties of durum and soft wheat. - Sci Rep. 7: 14839, 2017.

Fernandez, P., Di Rienzo, J.A., Moschen, S., Dosio, G.A.A.: Aguirrezábal, L.A.N., Hopp, H.E., Paniego, N., Heinz, R.A.: Comparison of predictive methods and biological validation for qPCR reference genes in sunflower leaf senescence transcript analysis. - Plant Cell Rep. 30: 63-74, 2011. 
Foyer, C.H., Noctor, G.: Ascorbate and glutathione: the heart of the redox hub. - Plant Physiol. 155: 2-18, 2001.

García-Garijo, A., Tejera, N.A., Lluch, C., Palma, F.: Metabolic responses in root nodules of Phaseolus vulgaris and Vicia sativa exposed to the imazamox herbicide. - Pest Biochem. Physiol. 111: 14-23, 2014.

Gaston, S., Zabalza, A., González, E.M., Arrese-Igor, C., Aparicio-Tejo, P.M., Royuela, M.: Imazethapyr, an inhibitor of the branched-chain amino acid biosynthesis, induces aerobic fermentation in pea plants. - Physiol. Plant. 114: 524$532,2002$.

Habig, W.H., Pabst, M.J., Jakoby, W.B.: Glutathione S-transferases. The first enzymatic step in mercapturic and acid formation. - J. biol, Chem 249: 7130-7713, 1974.

Jimenez, F., Fernandez, P., Rojano-Delgado, A.M., Alcantara, R., De Prado, R.: Resistance to imazamox in Clearfield soft wheat (Triticum aestivum L.). - Crop Protect. 78: 15-19, 2015.

Jozefczak, M., Remans, T., Vangronsveld, J., Cuypers, A.: Glutathione is a key player in metal-induced oxidative stress defences. - Int. J. mol. Sci. 13: 3145-3175, 2012.

Kaspar, M., Grondona, M., León, A., Zambelli, A.: Selection of a sunflower line with multiple herbicide tolerance that is reversed by the P450 inhibitor malathion. - Weed Sci. 59: 232237, 2011.

Kudsk, P., Kristensen, J.L.: Effect of environmental factors on herbicide performance. - In: Combellack J.H., Levich K.J., Richardson R.G. (ed): First International Weed Control Congress. pp. 173-186. Weed Science Society of Victoria, Melbourne 1992.

Lamoureux, G.L., Rusness, D.G.: Glutathione in the metabolism and detoxification of the xenobiotics in plants. - In: De Kok, L.J., Stulen, I., Rennenberg, H., Brunold, C., Rauser, W. (ed.): Sulfur Nutrition and Assimilation in Higher Plants. Pp. 221237. SPB Academic Publishers, The Hague 1993.

LaRossa, R.A., Schloss, J.V.: The sulfonylurea herbicide sulfometuron methyl is anextremelypotent and selective inhibitor of acetolacetate synthase in Salmonella typhimurium. - J. biol. Chem. 259: 8753-8757, 1984.

Lichtenthaler, H.K.: Chlorophylls and carotenoids: pigments of photosynthetic biomembranes. - Methods Enzymol. 148: 350382, 1987.

Manabe, Y., Tinker, N., Clville, A., Miki, B.: CSR1, the sole target of imidazolinone herbicide in Arabidopsis thaliana. Plant Cell Physiol. 9: 1340-1358, 2007.

Marrs, K.: The functions and regulation of glutathione S-transferases in plants. - Annu. Rev. Plant Physiol. Plant mol. Biol. 47: 127-158, 1996.

Mithila, J., Hall, J.C., Johnson, W.G., Kelley, K.B., Riechers, D.E.: Evolution of resistance to auxinic herbicides: historical perspectives, mechanisms of resistance, and implications for broadleaf weed management in agronomic crops. - Weed Sci. 59: 445-457, 2011

Monchiero, M., Gullino, M.L., Pugliese, M., Spadaro, D., Garibald,i A.: Efficacy of different chemical and biological products in the control of Pseudomonas syringae pv. actinidiae on kiwifruit. - Australasian Plant Pathol. 44: 13-23, 2015.

Ochogavia, A.C., Gil, M., Picardi, L., Nestares, G.: Precision phenotyping of imidazolinone-induced chlorosis in sunflower. - Breed. Sci. 64: 416-421, 2014.

Pfenning, M., Palfay, G., Guillet, T. The CLEARFIELD ${ }^{\circledR}$ technology - a new broad-spectrum post-emergence weed control system for European sunflower growers. - J. Plant Dis.
Prot. 21 (Special Issue): 649-653, 2008.

Qian, H., Lu, T., Peng, X., Han, X., Fu, Z.: Enantioselective phytotoxicity of the herbicide Imazethapyr on the response of the antioxidant system and starch metabolism in Arabidopsis thaliana. - Plos ONE 6: e 19451, 2011.

Quevel, G., Noctor, G.: A plate reader method for the measurement of NAD, NADP, glutathione and ascorbate in tissue extracts: application to redox profiling during Arabidopsis rosette development. - Anal Biochem, 363: 58-69, 2007.

Ray, T.: Site of action of chlorsulfuron: inhibition of valine and isoleucine biosynthesis in plants. - Plant Physiol. 75: 827-831, 1984.

Rojano-Delgado, A.M., Priego-Capote, F., De Castro, M.D.L., De Prado, R.: Mechanism of imazamox resistance of the Clearfield $^{\circledR}$ wheat cultivar for better weed control. - Agron. Sustain. Dev. 35: 639-648, 2015.

Rost, T.L.: The comparative cell cycle and metabolic effects of chemical treatments on root tip meristems. Chlorsulfuron. J. Plant Growth Regul. 3: 51-63, 1984.

Sala, C.A., Bulos, M., Altieri, E., Weston, B.: Response to imazapyr and dominance relationships of two imidazolinonetolerant alleles at the Ahasll locus of sunflower. - Theor. appl. Genet. 124: 385-396, 2012.

Scalla, R., Roulet, A.: Cloning and characterization of a glutathione S-transferase induced by a herbicide safener in barley (Hordeum vulgare). - Physiol. Plant. 116: 336-344, 2002.

Schröder, P., Götzberger, C.: Partial purification and characterization of glutathione S-transferase from leaves of Juniperus communis, Larix decidua and Taxus baccata. Appl. Bot. 71: 31-37, 1997.

Shaner, D.L.: Physiological effects of the imidazolinone herbicides. - In: Shaner, D.L., O'Connor, S.L. (ed.): The Imidazolinone Herbicides. Pp. 129-137. CRC Press, Boca Raton 1991.

Shaner, D.L.: Imidazolinone herbicides -. In: Plummer, D., Ragsdalr, N. (ed.): Encyclopedia of Agrochemicals. Pp. 769784. John Wiley and Sons, Hoboke 2003.

Shaner, D.L., Reider, M.L.: Physiological responses of com (Zea mays) to AC 243,997 in combination with valine, leucine and isoleucine. - Pest. Biochem. Physiol. 25: 248-257, 1986.

Sousa, C., Pinti J.J.O., Martinazzo, E.G., Perboni, A.T., Farias, M.E., Bacarini,. M.A.: Chlorophyll $a$ fluorescence in rice plants exposed of herbicides of group imidazolinone. - Planta Daninha 32: 141-150, 2013.

Vandesompele, J., De Preter, K., Pattyn, F., Poppe, B., Van Roy, N., De Paepe, A., Speleman, F.: Accurate normalization of real-time quantitative RT-PCR data by geometric averaging of multiple internal control genes. - Genome Biol. 3: 0034.10034.11, 2002.

Vercampt, H., Koleva, L., Vassilev, A., Horemans, N., Biermans, G., Vangronsveld, J., Cuypers, A.: The functional role of the photosynthetic apparatus in the recovery of Brassica napus plants from preemergent metazachlor exposure. J. Plant Physiol. 196: 99-105, 2016.

Yuan, J.S., Tranel, P.J., Stewart, N., Jr.: Non-target-site herbicide resistance: a family business. - Trends Plant Sci. 12: 6-13, 2006.

Zabalza, A., Gaston, S., Orcaray, L., Royuela, M.: Carbohydrate accumulation in leaves of plants treated with the herbicides chlorsulfuron or IM is due to a decrease in sink strength. - J. Agr. Food Chem. 52: 7601-7606, 2004. 